\title{
SOCIAL REALITY FORMATION IN MEDIA DISCOURSE: INFORMATION AMBIGUITY STRATEGY ${ }^{1}$
}

\author{
Vladimir I. Ozyumenko \\ Peoples' Friendship University of Russia, Moscow, Russia
}

\begin{abstract}
Modern media have become an important ideological tool in conveying and forming a certain view of the world and attitude towards it. While complying with the interests of the power structures, they shape public opinion by means of increasingly sophisticated media technologies and techniques. The article introduces multilevel means of creating ambiguity of a media text: verbs with the semantic component 'without proof', lexical units with semantics of uncertainty, means of expressing epistemic modality, interrogative headings, etc. The regular use of these means observed in the media enables the author to consider ambiguity as one efficient strategy of public opinion manipulation. The data for the study were obtained from quality British and American newspapers and news websites that cover events related to Russia. By using the methods of linguistic pragmatics and sociolinguistics as well as critical discourse analysis, it was proved that the ambiguity is a widely spread method in modern media, it enables journalists to write about unconfirmed facts and introduce a certain attitude towards them into the minds of the audience without bearing any responsibility for unsubstantiated information.
\end{abstract}

Key words: media discourse, persuasion, manipulation, ambiguity, public opinion, English.

Citation. Ozyumenko V.I. Social Reality Formation in Media Discourse: Information Ambiguity Strategy. Vestnik Volgogradskogo gosudarstvennogo universiteta. Seriya 2. Yazykoznanie [Science Journal of Volgograd State University. Linguistics], 2019, vol. 18, no. 3, pp. 64-75. (in Russian). DOI: https://doi.org/10.15688/jvolsu2.2019.3.5

\section{КОНСТРУИРОВАНИЕ СОЦИАЛЬНОЙ РЕАЛЬНОСТИ В МЕДИАДИСКУРСЕ: СТРАТЕГИЯ ИНФОРМАЦИОННОЙ НЕОДНОЗНАЧНОСТИ ${ }^{1}$}

\author{
Владимир Иванович Озюменко \\ Российский университет дружбы народов, г. Москва, Россия
}

\begin{abstract}
Аннотация. Современные СМИ стали важным идеологическим инструментом, конструирующим и передающим определенный взгляд на мир и отношение к нему. Выполняя заказ власти, они формируют общественное мнение, используя для этого все более утонченные медийные технологии и приемы. В статье представлены результаты исследования, в ходе которого были выявлены разноуровневые средства создания неоднозначности медийного текста: глаголы с семантическим компонентом 'without proof', лексические единицы с семантикой неопределенности, средства выражения эпистемической модальности, вопросительные заголовки и др. Регулярность их употребления позволила автору квалифицировать неоднозначность как одну из стратегий манипулирования общественным мнением. Исследование было выполнено на материале качественных британских и американских СМИ, которые освещают события, связанные с Россией, и формируют отношение к ней. Результаты анализа, проведенного с применением методов лингвопрагматики, социолингвистики и критического дискурс-анализа, показали, что в современных англоязычных СМИ ض் широко используется стратегия неоднозначности. Она дает возможность журналистам писать о ничем не подкрепленных фактах, внедрять в сознание аудитории определенное отношение к ним, избегая при этом ответственности за распространение неподтвержденной информации.
\end{abstract}

Ключевые слова: медиадискурс, убеждение, манипуляция, неоднозначность, общественное мнение, английский язык. 
Цитирование. Озюменко В. И. Конструирование социальной реальности в медиадискурсе: стратегия информационной неоднозначности // Вестник Волгоградского государственного университета. Серия 2. Языкознание. - 2019. - Т. 18, № 3. - C. 64-75. - DOI: https://doi.org/10.15688/jvolsu2.2019.3.5

\section{Введение}

Взгляд на язык как деятельность [Земская, 2004; Постовалова, 1982; Austin, 1976; Searl, 1969; и др.] позволил признать за ним активную роль в конструировании социально-культурного мира и мышления [Гайда, 2014, с. 10]. В настоящее время общепризнанным является тот факт, что язык используется не только как средство выражения мысли и осуществления коммуникации, но и как важный идеологический инструмент, передающий и конструирующий определенный взгляд на мир. Большую роль в этом играет язык средств массовой информации [Dijk, 2009, p. 8]. Высказанная почти сто лет назад идея о том, что пресса оказывает существенное влияние на формирование общественного мнения, определение нашей «когнитивной карты мира» ('cognitive map of the world') [Lippmann, 1922] не только не потеряла своей значимости, но и, благодаря современным техническим средствам, стала еще более актуальной. Особая роль СМИ, которые по праву считаются четвертой властью, обусловливается их прямым выходом на широкую аудиторию, что дает им большие возможности в формировании общественного мнения. Хотя основная функция массмедиа по-прежнему заключается в том, чтобы информировать и просвещать, то есть служить информационным мостом между событиями и обществом, в современном социуме медийный дискурс становится все более обремененным идеологическим содержанием, выступает как социальная сила, обычно действующая в поддержку интересов различных экономических и политических элит [White, 2000, p. 379].

Объективность СМИ и достоверность передаваемой информации традиционно являются в журналистике базовой ценностью. Однако в последнее время мы становимся свидетелями того, как пресса создает дискурс, который согласуется со взглядами, выгодными власти. Это касается и так называемых свободных СМИ в демократическом обществе. Исследования, проводимые в рамках критического дискурс-анализа, политической лингвистики и медиадискурса, содержат многочисленные факты того, как и при помощи каких средств пресса способствует внедрению нужных власти идей в сознание общества (см.: [Иванова, 2016; Солопова, Чудинов, 2018; Чернявская, 2006; Чудинов, 2006; Fairclough, 1989; Fowler, 1991; Wodak, 2007; и др.]).

Значимость СМИ в современном мире определяется еще и тем, что именно журналисты выбирают темы для общественного обсуждения. Т.Г. Добросклонская справедливо называет отбор фактов одной из эффективных медиатехнологий, связанных с идеологической функцией, отмечая, что он позволяет интерпретировать события, расставлять политические акценты, служит действенным инструментом информационной политики, а также может использоваться как мощное оружие для ведения информационной войны [Добросклонская, 2009, с. 89]. Так, среди активно обсуждаемых в последнее время в западных СМИ событий можно назвать дела Скрипалей и Бутиной, вмешательство России в выборы в США, которое на данный момент так и не получило своего подтверждения. Освещая эти события, пресса выполняет информационную функцию, однако то, как эти события преподносятся и часто упоминаются, свидетельствует о том, что СМИ прямо или косвенно дают им оценку и показывают социуму, как именно их нужно воспринимать и оценивать.

Общественное мнение формируется посредством разнообразных способов и приемов воздействия на аудиторию, которые становятся все более утонченными [Иванова, Чанышева, 2014; Комалова, 2019; Чернявская, 2006; Шейгал, 2004; McCombs, Reynolds, 2002; и др.], при этом они нередко принимают агрессивную форму [Озюменко, 2017]. В современном медийном дискурсе наблюдается смещение от прямого убеждения к манипуляции, являющейся видом эффективного скрытого воздействия на сознание, при котором подавляется рациональное восприятие информации адресатом и навязываются заданные смыслы [Клушина, 2008 , с. 45]. Адресат при этом не может сопротивляться манипуляции и становится ее 
жертвой [Dijk, 2006, p. 361]. Манипулятивное воздействие осуществляется «путем искусного использования определенных ресурсов языка с целью скрытого влияния на когнитивную и поведенческую деятельность адресата» [Копнина, 2014, с. 25]. Другими словами, манипуляция - это «использование скрытых возможностей языка с целью навязать адресату определенное представление о действительности, сформировать нужное отношение к ней, вызвать необходимую оценку, эмоциональную или поведенческую реакцию» [Озюменко, 2017, с. 206]. Как показали проведенные исследования, манипулятивное воздействие осуществляется при помощи многообразных стратегий и тактик, различных языковых и неязыковых средств (см.: [Иванова, Садуов, 2008; Кара-Мурза, 2004; Копнина, 2014; Ларина, Озюменко, Пономаренко, 2011; Сковородников, Копнина, 2012; Шейгал, 2004; Chilton, 2011; Dijk, 2006; и др.]).

В данной статье анализируются разноуровневые языковые средства выражения неоднозначности, рассматриваемой в качестве стратегии манипулирования, поскольку адресату предоставляется информация, подлинность которой не доказана, однако в силу особенностей восприятия текста она остается в его памяти как достоверная и влияет на мировосприятие. Стратегия неоднозначности широко применяется в последнее время для освещения событий, в той или иной мере касающихся России, что, с одной стороны, позволяет СМИ избегать обвинений в том, что они распространяют непроверенные сведения, a с другой - дает возможность влиять на общественное мнение, формируя негативный образ России.

\section{Материал и методология исследования}

Материал для исследования извлечен из британских и американских газет (The Economist, The Guardian, The Financial Times, The Telegraph, The Washington Post, The New York Times и др.), текстов новостных сайтов (BBC, Reuters, Fox News, Politico) и других источников информации, которые освещают события, касающиеся России.

С использованием методов социолингвистики, лингвопрагматики и критического дис- курс-анализа [Critical DiscourseAnalysis..., 2007; Dijk, 2006; 2009; Fairclough, 1995; 2001; Methods of Critical Discourse Analysis, 2001; Wodak, 2007; и др.] в исследовании рассматриваются медийные приемы и языковые средства создания неопределенности и неоднозначности в газетных текстах (отбор информации, ее тиражирование, умолчание фактов, слова, содержащие в своей семантике компонент 'неопределенность', средства эпистемической модальности, пассивный залог, вопросительные заголовки и др.), а также прагматическая пресуппозиция [Bekalu, 2006; Fairclough, 1995; Levinson, 1983].

\section{Неоднозначность в текстах СМИ}

Достоверность передаваемой информации в существенной мере зависит от качества СМИ. В так называемой «желтой» прессе она значительно ниже, чем в качественных изданиях. Однако в последнее время исследователи обращают внимание на тенденцию к использованию и в качественной прессе сведений, полученных «из вторых рук», на отсутствие источника информации, неточности в передаваемых новостях, умолчание (см. например: [Клушина, 2008; Clark, 2010]), что приводит к неопределенности и неоднозначности медийных текстов.

Рассмотрим пример:

(1) US officials believe that Russia was responsible for causing mysterious brain injuries to American diplomats in Cuba, it was claimed yesterday (The Times, 12.09.2018) - 'Американские чиновники считают, что Россия была ответственна за причинение таинственных мозговых травм американским дипломатам на Кубе, было заявлено вчера' (Здесь и далее преднамеренно дается буквальный перевод, поскольку это позволяет точнее передать содержание оригинального текста).

Очевидно, что данное заявление недостоверно. В нем отсутствуют как сведения об источнике заявления, так и конкретная информация об американских чиновниках и травмах, которые названы таинственными. Однако, печатая такой материал, журналисты показывают, что верят или, во всяком случае, допускают, что он правдив. Суждения подобного рода, которые не подкреплены фактами, 
но могут быть восприняты как истинные, мы квалифицируем как неоднозначные (неопределенные, двусмысленные).

Согласно В. Эмпсону, неопределенность (двусмысленность) состоит, главным образом, в существовании двух возможных интерпретаций слова или предложения, между которыми читатель вынужден выбирать [Empson, 1966]. В приведенном примере (1) предложение можно толковать на основе, во-первых, пропозиции, отражающей положение дел в реальном мире (например, по вине России были причинены таинственные травмы мозга американским дипломатам), во-вторых, модальной версии данного суждения: возможно, некоторые американские чиновники думают / верят / считают / предполагают, что в таинственном происшествии виновата Россия. Особое внимание здесь следует обратить на глагол to believe ('верить, считать'), в семантике которого, как это следует из его словарной дефиниции, есть компонент 'without proof' ('без доказательств'): «accept that something is true, especially without proof» (OELD).

Важно отметить, что то или иное суждение может восприниматься как истинное в результате самого факта его появления в СМИ. Среднестатистический получатель информации, в принципе признающий, что не все то сообщения СМИ соответствуют действительности, часто не имеет ни времени, ни желания разбираться в их достоверности. Хотя он не обязательно верит всему, что сообщают СМИ, его знание о мире в значительной степени обусловлено именно этой информацией [Клушина, 2014; Gilbert, Tafarodi, Malone, 1993]. Если же та или иная необоснованная новость повторяется многократно, она и вовсе перестает ставиться под сомнение и степень ее достоверности в восприятии аудитории возрастает.

\section{Языковые средства создания неоднозначности в тексте СМИ}

\section{Глаголы с семантическим компонентом 'without proof'}

Среди активно используемых лексических средств, которые могут создавать неоднозначность суждения, мы выделили глаголы believe, claim, allege, suggest, являющиеся глаголами мышления и используемые для выражения восприятия мира человеком. Словарные дефиниции этих глаголов (CD; $\mathrm{MD}$; OELD) показывают, что помимо основного значения у всех есть дополнительный семантический компонент 'without proof'. Получателю информации, который обращает внимание главным образом на основное значение глагола, данный компонент представляется не столь очевидным, он, как правило, не актуализируется, а иногда нивелируется, однако для манипулятивных целей имеет важное значение. Рассмотрим данные глаголы подробнее.

Глагол claim определяется следующим образом: «to say that something is true or is a fact, although you cannot prove it and other people might not believe» (CD) ('сказать, что что-то является правдой или фактом, хотя вы не можете этого доказать, а другие люди могут этому не верить'):

(2) Several Russian suspects have been identified in the Salisbury spy assassination attempt after the nerve agent used was found in a perfume bottle, it is claimed (The Times, 20.07.2018) -'Несколько российских подозреваемых были обвинены в покушении на шпиона в Солсбери после того, как использованный нервнопаралитический газ был обнаружен во флаконе с духами, утверждается’.

Глагол claim в данном случае употреблен в пассивной конструкции с отсутствующим агенсом в конце предложения как запоздалый комментарий к основной части сообщения, касающегося умозрительных предположений о попытке убийства бывшего российского шпиона. Читателя, вероятнее всего, заинтересует предшествующая информация, а тот факт, что она приводится без доказательств и неизвестно кем, останется незамеченным.

Глагол allege (как и его производные alleged, allegation, allegedly) также имеет в своей дефиниции семантический компонент 'without proof': «to say that someone has done something illegal or wrong without giving proof» (CD) ('сказать, что кто-то совершил что-то незаконное или неправильное без предоставления доказательств'), причем этот компонент включен в толкование, то есть является частью лексического значения глагольной едини- 
цы, а следовательно, всегда актуализируется в контексте:

(3) Prosecutors have alleged that she used her relationship with the unnamed American political operative, with whom she was living, "as simply a necessary aspect" of her covert activities on behalf of Russia (Los Angeles Times, 19.07.2018) - 'Прокуроры утверждают, что она использовала свои отношения с неназванным американским политиком, с которым жила с целью скрыть свою деятельность, проводимую в пользу России';

(4) The federal indictment, brought by special counsel Robert Mueller, represents the most detailed allegations to date of illegal Russian meddling during the campaign that sent Trump to the White House (Chicago Tribune, 17.02.2018) - 'Федеральное обвинительное заключение, предъявленное специальным прокурором Робертом Мюллером, представляет собой наиболее подробные на сегодняшний день обвинения (необоснованные обвинения. B. O.) в незаконном вмешательстве русских во время кампании, приведшей Трампа в Белый дом'.

Пример (4) требует особого комментария, поскольку в нем используется определение detailed, которое означает наличие многих фактов и обычно употребляется со словами analysis, description, information, investigation, study (MD), то есть детальным может быть анализ, описание, расследование, информация, изучение. В отношении обвинения detailed предполагает наличие фактов, цифр, дат и других объективных данных в поддержку обвинения, что логически не согласуется со значением лексемы allegation ('голословное утверждение'). Подобная комбинация несочетаемых слов вряд ли может быть случайной. Хотя суждение (4) по сути неоднозначно, слово detailed создает у читателя впечатление доказательности и наводит на мысль о вине России.

(5) The allegations included claims that the Russians' operations “included supporting the presidential campaign of then-candidate Donald J. Trump and disparaging Hillary Clinton" (The Guardian, 23.07. 2018) - 'Обвинения содержали утверждения о том, что действия русских «включали поддержку президентской кампании тогдашнего кандидата Дональда Дж. Трампа и оскорбление Хиллари Клинтон»'.

В примере (5) употреблены две лексемы с семантическим компонентом 'without proof' - allegations и claims: недоказанные обвинения (allegations) включают не имеющие доказательств заявления (claims). Однако семантический компонент 'without proof' не актуализируется и в сознании читателя, вероятно, останутся: русские / поддержка Трампа / оскорбление Хиллари Клинтон.

Глагол suggest в одном из значений также содержит семантический компонент 'without proof': «communicate or show an idea or feeling without stating it directly or giving proof»» (CD). В медийных текстах to suggest часто встречается именно в этом значении:

(6) The same documents suggest the Russian embassy extended a further four invitations to Brexit's biggest funder, but it is not known if they were accepted (The Observer, 08.08.2018) - 'Те же документы говорят / наводят на мысль, что российское посольство направило еще четыре приглашения крупнейшему спонсору Brexit, но неизвестно, были ли они приняты'.

Здесь рассматриваемый глагол выражает значение, противоположное значению словосочетания but it is not known, что способствует усилению истинности первой части пропозиции. Если не известно, были ли приглашения приняты, то заявление о том, что они были направлены, уже воспринимается как истинное.

К рассматриваемой группе можно отнести и глагол appear: «come into sight; become visible or noticeable, especially without apparent cause, seem»; "give the impression of somethingbeing» (OELD) ('появиться в поле зрения; стать видимым или заметным, особенно без видимой причины, казаться; создать впечатление чего-то существущего'):

(7) After the statement's release, Donald Trump said that Russia appeared to be behind the attack (Guardian, 15.03.2018) - 'После выхода заявления Дональд Трамп сказал, что Россия, видится (вероятно, стоит) за атакой’.

Хотя данный глагол в соответствии со своей семантикой создает только впечатление чего-то существующего, последствия предположений, приведенных в (7), как известно, оказались более чем серьезными (высылка из Великобритании российских дипломатов, введение санкций и др.). 
Подчеркнем, что восприятие фактического содержания сообщений требует меньших усилий со стороны читателей, чем анализ семантики рассматриваемых глаголов. Отмеченные семантические детали, как правило, остаются на периферии сознания и не привлекают внимания аудитории.

\section{Языковые единицы, выражающие} неопределенность источника информации и субъектов действия

Рассмотренные выше глаголы, наряду с некоторыми другими (например, say, report, know, seem), часто используются в типичных для медийных текстов инфинитивных конструкциях (Nominative-with-the-Infinitive construction), которые усиливают неоднозначность, так как субъект действия или источник информации в них часто опускается:

(8) It is believed that this may have been carried out by GRU and may have continued after that date (Independent, 14.03. 2018) -'Считается, что это могло быть выполнено ГРУ и могло продолжаться после этой даты’.

Как отмечается в словарях, формула «someone / something is believed to be» используется для выражения того, что достоверность чего-то является общим мнением большинства людей, хотя это и не было доказано: «it is the general opinion of most people that something is true although it has not been proved» (MD). Словосочетание most people в толковании эксплицирует высокую вероятность истинности суждения и позволяет утверждать, что читатель воспримет высказывание с конструкцией «someone / something is believed to be» как правдивое.

Неопределенность источника или участников ситуации создается также использованием неопределенных местоимений some, one, someone, somebody (some officials 'некоторые чиновники', some sources 'некоторые источники', someone in Putin's circle 'кто-то из окружения Путина' и т. д.); неопределенного или нулевого артикля (a senior Russian lawmaker 'некий высокопоставленный российский законодатель', an investigator 'некий следователь'); а также выражений unnamed officials 'неназванные официальные лица', unidentified person 'неустановленное лицо', unconfirmed reports 'неподтвержденные сообщения' [Ozyumenko, Larina, 2018]. В результате употребления перечисленных языковых единиц и конструкций создается неясность того, кто служит источником информации или исполнителем называемого действия:

(9) Some sources have linked GRU agents to the downing of Malaysian airlines flight MH17 (The Guardian, 06.08.2018) - 'Некоторые источники связывают агентов ГРУ с падением малазийского лайнера МН17';

(10) For the first time, prosecutors also linked Ms. Butina to an unnamed wealthy Russian oligarch who they said has deep ties to the Kremlin's presidential administration and often travels to the United States (The New York Times, 28.07.2018) 'Впервые прокуроры также связали г-жу Бутину с неназванным богатым российским олигархом, который, по их словам, имеет тесные связи с президентской администрацией Кремля и часто ездит в Соединенные Штаты'.

\section{Языковые единицы, выражсающие эпистемическую модальность}

Языковые единицы, выражающие эпистемическую модальность, являются еще одним средством создания неоднозначности, неопределенности, поскольку выражают разную степень вероятности, позволяя говорить о действии, совершение которого не доказано. Среди них прежде всего следует отметить модальные глаголы could, may, might.

(11) Trump himself has been reluctant to acknowledge the interference and any role that it might have played in propelling him to the White House (Chicago Tribune 17.02.18) - 'Сам Трамп неохотно признавал вмешательство [в выборы] и ту роль, которую оно, возможно, сыграло в продвижении его в Белый дом';

(12) The prime minister told the UK's allies that such an attack could have taken place on the streets of any of their cities (Guardian, 15.03.2018) - 'Премьер-министр сказала союзникам Великобритании, что такая атака могла иметь место на улицах любого из их городов'.

В примере (11) глагол might обозначает действие, которое, возможно, вообще не имело места, а в (12) глагол could выражает дей- 
ствие, совершение которого возможно гипотетически.

По нашим наблюдениям, широкое распространение в текстах СМИ получили прилагательные и наречия, указывающие на вероятность действия: possible, possibly, probably, presumably, likely и др. Эти единицы позволяют авторам утверждать истинность практически всего, о чем они пишут, и избегать обвинений в предоставлении ложной информации:

(13) A public inquiry concluded in 2016 that Putin had probably approved the killing (Guardian, 04.04.2018) - 'Публичное расследование в 2016 году пришло к заключению, что Путин, вероятно, одобрил убийство';

(14) Russia experts said the Kremlin was likely behind the effort (Politico, 16.02.2018) - 'Эксперты по России заявили, что Кремль, вероятно, стоит за этими действиями'.

Данные прилагательные и наречия могут сочетаться с языковыми единицами, выражающими меру и степень проявления признака, что усиливает восприятие упомянутого в высказывании действия как действительно совершенного: highly likely 'с высокой вероятностью', more than likely 'более, чем вероятно', most likely, overwhelmingly likely 'в высшей степени вероятно', almost certain (ly) 'почти наверняка'. Можно предположить, что чем меньше соответствует истине навязываемая обществу идея, тем больше усиливается степень ее вероятности средствами языка. Так, всего через неделю после инцидента в Солсбери, при отсутствии какихлибо доказательств Тереза Мей произнесла ставшее впоследствии широко тиражируемым выражение highly likely 'весьма вероятно', говоря о том, что Россия несет ответственность за нападение на Сергея Скрипаля и его дочь Юлию, и предупредила, что Великобритания не потерпит такой «наглой попытки убить ни в чем не повинных гражданских лиц на нашей земле»:

(15) After chairing a meeting of the national security council, the prime minister told MPs that it was "highly likely" that Russia was responsible for the attack on Sergei Skripal and his daughter, Yulia. She warned that Britain would not tolerate such a "brazen attempt to murder innocent civilians on our soil” (The Guardian, 13.03.2018) - 'После проведения заседания Совета национальной безопасности, премьер-министр сказала депутатам, что «весьма вероятно», что Россия несет ответственность за нападение на Сергея Скрипаля и его дочь Юлию. Она предупредила, что Великобритания не потерпит такой «наглой попытки убить мирных жителей на нашей земле»'.

Подобное заключение сделало и правительство Великобритании:

(16) ...The government has concluded that it is highly likely that Russia was responsible for the act against Sergei and Yulia Skripal (The Guardian, 13.03.2018) - ' ...Правительство пришло к выводу, что весьма вероятно, что Россия была ответственна за акт нападения на Сергея и Юлию Скрипаль'

Через несколько дней министр иностранных дел Борис Джонсон пошел еще дальше, заявив, что решение использовать нервнопаралитический газ против бывшего шпиона «в высшей степени вероятно» (overwhelmingly likely) является личным решением российского президента Владимира Путина:

(17) Foreign Secretary Boris Johnson of Britain said on Friday that it was "overwhelmingly likely" that President Vladimir V. Putin of Russia personally ordered the nerve agent attack against a former Russian spy this month (The New York Times, 16.03.2018) 'Министр иностранных дел Великобритании Борис Джонсон заявил в пятницу, что «в высшей степени вероятно», что президент России Владимир Путин лично отдал приказ о нападении с применением нервнопаралитического газа на бывшего российского шпиона в этом месяце'.

Шесть месяцев спустя, по-прежнему при отсутствии доказательств участия России в данном инциденте, Тереза Мей заявила, что нападение на Скрипалей «почти наверняка» (almost certain) было совершено по указанию сверху, а г-н Уоллес уже без всякого сомнения утверждает, что Путин несет за это прямую ответственность:

(18) Mrs May said that it was "almost certain" the attack on the former Russian spy Sergei Skripal, 67, and his daughter, Yulia, 34, was authorised by someone senior outside the GRU, the Russian military intelligence agency. However, Mr Wallace said that Mr 
Putin bore direct responsibility(The Times, 06.09.2018) 'Миссис Мей сказала, что «почти наверняка» нападение на бывшего российского шпиона Сергея Скрипала, 67 лет, и его дочь Юлию, 34 года, было санкционировано кем-то высокопоставленным и не из ГРУ, российского агентства военной разведки. Однако г-н Уоллес сказал, что прямую ответственность за это несет господин Путин'.

Выражения, создающие эффект неоднозначности, в устах высокопоставленных политиков звучат неуместно и даже иронично. Однако энтузиазм СМИ при тиражировании таких высказываний британских лидеров не оставляет сомнений в том, что четвертая власть выступает единым фронтом с государственной властью. Несмотря на наличие в выражениях политических деятелей Великобритании языковых средств со значением эпистемической модальности, можно сказать, что навязывание обществу идеи о вине России носит в данном случае агрессивный характер (подробно об этом см.: [Озюменко, 2017]).

Как показал проведенный анализ, в медийных текстах часто наблюдается комбинация разноуровневых средств со значением неопределенности, что усиливает неоднозначность высказывания, снимая с журналиста ответственность за недостоверность фактов, и тем самым дает больше возможности озвучивать самые невероятные идеи:

(19) Though an indictment is a charge only, it presumably relies on hard evidence of a wide and deep Russian project - so wide and so deep that it could only have been approved and paid for by the Kremlin (Fox News, 22.02. 2018) - 'Хотя обвинительное заключение - это всего лишь обвинение, оно, по-видимому, опирается на убедительные доказательства широкого и глубокого российского проекта - настолько широкого и глубокого, что он мог быть одобрен и оплачен только Кремлем'.

Высказывание содержит обвинение России во вмешательстве в президентские выборы в США. При отсутствии какой-либо аргументации в нем использованы две единицы с модальным значением: presumably 'по-видимому' ('обвинение, по-видимому, опирается на убедительные доказательства') и could 'мог бы' ('проект мог быть одобрен и оплачен только Кремлем’). Однако, просматривая статью, читатель вряд ли обратит на них внимание. В его долгосрочной памяти останутся: российский проект / убедительные доказательства / Кремль / вмешательство в выборы.

\section{Вопросительные заголовки}

Эффективным средством подачи неподтвержденного материала и в то же время воздействия на аудиторию являются вопросительные заголовки [Озюменко, 2017; Ozyumenko, Larina, 2017; 2018]. Заголовки в целом - важная часть медийного дискурса. Знакомясь с новостями, читатель в первую очередь просматривает их. Они не только передают информацию, но и заостряют внимание на наиболее важных для СМИ фактах. Заголовки в форме вопроса занимают здесь особое место: представляя факты / события в виде вопроса, пресса не претендует на их достоверность, однако в таких заголовках содержится определенная пресуппозиция.

(20) Has Russia carried out state-sponsored assassinations in the UK? (Guardian, 04.08.2018) 'Осуществляла ли Россия спонсируемые государством убийства в Великобритании?';

(21) Does Russia present a credible threat to the UK? (Guardian, 15.03.2018) - 'Представляет ли Россия реальную угрозу для Великобритании?’.

В приведенных примерах содержится негативная пресуппозиция о том, что Россия спонсирует убийства в других странах (20), несет в себе реальную угрозу (21) и потому есть причины ее бояться. Данная пресуппозиция усиливается еще и тем, что перед словами assassinations («убийство») и threat («угроза») стоят определения (state-sponsored assassinations, credible threat), которые «перетягивают» на себя вопрос, повышая таким образом степень достоверности реалий, называемых существительными.

\section{Заключение}

В исследовании был поставлен вопрос о том, как информационный текст, прямая цель которого состоит в описании текущих событий, при помощи различных технологий все чаще используется для манипуляции общественным сознанием. Выявлена значимость таких при- 
емов конструирования социальной реальности, как отбор информации, частотность ее тиражирования даже в случае неподтвержденности, отсутствие или преднамеренное умолчание фактов, двусмысленность суждений.

Системность и регулярность употребления языковых средств, создающих неопределенность и двусмысленность текста, позволяют считать неоднозначность в современном медийном дискурсе одной из стратегий манипулирования. Она дает возможность журналистам писать о неподтвержденных фактах и не нести ответственности за распространение недостоверной информации, оказывая при этом существенное влияние на формирование общественного мнения.

Суждения, подобные тем, что были приведены в качестве примеров, как правило, закрепляются в сознании людей в силу того, что появляются в СМИ независимо от реализации в текстах эпистемической модальности. Кроме того, при чтении или просматривании текста читатели, в своем большинстве, не обращают внимания на «модальные нюансы», в их сознании фиксируются утверждаемые в прессе факты и формируются создаваемые ею образы. Выделенные средства неопределенности, которые используются журналистами для своей подстраховки, как правило, не попадают в сферу внимания читателя или не задерживаются в его сознании. Это дает некоторую свободу СМИ и делает их эффективным проводником идей властных структур, формирующих общественное мнение.

\section{ПРИМЕЧАНИЕ}

\author{
${ }^{1}$ Публикация подготовлена при поддержке \\ Программы РУДН «5-100». \\ The study was carried out in the framework of \\ “5-100” Project RUDN Program.
}

\section{СПИСОК ЛИТЕРАТУРЫ}

Гайда С., 2014. Философия стиля // Дискурс и стиль: теоретические и прикладные аспекты : коллектив. моногр. / под. ред. Г. Я. Солганика, Н. И. Клушиной, Н. В. Смирновой. М. : Флинта : Наука. С. 9-17.

Добросклонская Т. Г., 2009. Лингвистические способы выражения идеологической модальности в медиатекстах // Вестник Московского университета. Серия 19: Лингвистика и межкультурная коммуникация. № 2. С. 85-94.

Земская Е. А., 2004. Язык как деятельность : Морфема. Слово. Речь. М. : Яз. слав. культуры. $688 \mathrm{c}$.

Иванова С. В., 2016. Лингвистическая ресурсная база информационной войны: создание эффекта демонизации // Политическая лингвистика. № 5 (59). С. 28-37.

Иванова С. В., Садуов Р. Т., 2008. Политическая коммуникация как образец речевого манипулирования // Политическая лингвистика. № 2 (25). C. 52-59.

Иванова С. В., Чанышева 3. 3., 2014. Технологии дискурсивного оформления слухов в политическом дискурсе массмедиа // Политическая лингвистика. № 2. С. 39-49.

Кара-Мурза С. Г., 2004. Манипуляция сознанием. М. : Алгоритм. 528 c.

Клушина Н. И., 2008. Стилистика публицистического текста. М : МедиаМир. 244 с.

Клушина Н. И., 2014. Этические аспекты массовой коммуникации // Вестник Российского университета дружбы народов. Серия: Лингвистика. № 1. С. 59-66.

Комалова Л. Р., 2019. Репрезентация вербального образа акта агрессии в информационном универсуме англоязычных СМИ // Вестник Российского университета дружбы народов. Серия: Лингвистика. Т. 23, № 1. С. 149-164.

Копнина Г. А., 2014. Речевое манипулирование. М. : Флинта : Наука. 170 c.

Ларина Т. В., Озюменко В. И., Пономаренко Е. Б., 2011. Языковые механизмы манипулирования общественным мнением в английских и русских информационных текстах // Вестник Российского университета дружбы народов. Серия: Лингвистика. № 1. С. 28-37.

Озюменко В. И., 2017. Медийный дискурс в ситуации информационной войны: От манипуляции - к агрессии // Вестник Российского университета дружбы народов. Серия: Лингвистика. Т. 21, № 1. С. 203-220.

Постовалова В. И., 1982. Язык как деятельность. Опыт интерпретации концепции В. Гумбольдта. М. : Наука. 223 с.

Сковородников А. П., Копнина Г. А., 2012. Тексты СМИ как поле речевых манипуляций и их разоблачений (на материале российской прессы) //Лингвистика речи. Медиастилистика : коллектив. моногр., посвящ. 80-летию проф. Г.Я. Солганика. М. : Флинта. С. 467-492.

Солопова О. А., Чудинов А. П., 2018. Диахронический анализ метафор в британском корпусе текстов: колокола победы и Russia's V-Day // Вестник Российского университета друж- 
бы народов. Серия: Лингвистика. Т. 22, № 2. С. $313-337$.

Чернявская В. Е., 2006. Дискурс власти и власть дискурса. Проблемы речевого воздействия. М. : Флинта. 136 с.

Чудинов А. П., 2006. Политическая лингвистика. М. : Флинта : Наука. 256 с.

Шейгал Е. И., 2004.Семиотика политического дискурса. М. : Гнозис. 326 с.

Austin J. L., 1976. How to Do Things with Words. $2^{\text {nd }}$ ed. Oxford ; New York : Oxford University Press. $192 \mathrm{p}$.

Bekalu M. A., 2006. Presupposition in news discourse // Discourse and Society. Vol. 17, no. 2. P. 147-172.

Chilton P., 2011. Manipulation // Discursive Pragmatics / J. Zienkowski, J. O. Östman, J. Verschueren (eds.). Amsterdam and Philadelphia : John Benjamins. P. 176-189.

Clark C., 2010. Evidence of evidentiality in the quality press 1993 and 2005 // Corpora. Vol. 5, no. 2. P. $139-160$.

Critical Discourse Analysis: Theory and Interdisciplinarity, 2007 / G. Weiss, R. Wodak (eds.). London, Basingstoke, New York : Palgrave Macmillan. $336 \mathrm{p}$.

Dijk T. A. van, 2006. Discourse and manipulation // Discourse and Society. Vol. 17, iss. 3. P. 359-383.

Dijk T. A. van, 2009. Society and Discourse. How Social Contexts Influence Text and Talk. Cambridge : Cambridge University Press. 287 p.

Empson W., 1966. Seven Types of Ambiguity. N.Y. : New Directions. $256 \mathrm{p}$.

Fairclough N., 1989. Language and Power. Harlow ; N.Y. : Longman. 259 p.

Fairclough N., 1995. Critical Discourse Analysis: The Critical Study of Language. Harlow : Longman. 265 p.

Fairclough N., 2001. Critical discourse analysis as a method in social scientific research // Methods of Critical Discourse Analysis / R. Wodak, M. Meyer (eds.). L. : Thousand Oaks ; New Delhi : Sage. P. 121-139.

Fowler R., 1991. Language in the News. L. ; N.Y. : Routledge. 254 p.

Gilbert D. T., Tafarodi R. W., Malone P. S., 1993. You can't not believe everything you read // Journal of Personality and Social Psychology. Vol. 65, № 2. P. 221-233.

Levinson S., 1983. Pragmatics. Cambridge : Cambridge University Press. $420 \mathrm{p}$.

Lippmann W., 1922. Public Opinion. N.Y. : Macmillan. $427 \mathrm{p}$.

McCombs M., Reynolds A., 2002. News influence on our pictures of the world // Media Effects: Advances in Theory and Research / J. Bryant,
D. Zillman (eds.). Mahwah New Jersey : L. Elbaum Associates. P. 1-18.

Methods of Critical Discourse Analysis, 2001 / R. Wodak, M. Meyer (eds.). London, Thousand Oaks ; New Delhi : Sage. 200 p.

Ozyumenko V., Larina T., 2017. From manipulation to aggression: analysis of media discourse in the situation of information confrontation $/ / 4^{\text {th }}$ International Multidisciplinary Scientific Conference on Social Sciences and Arts SGEM 2017. Vienna, HOFBURG Congress Centre, book 3, vol. 2. P. 737-744.

Ozyumenko V., Larina T., 2018. How to understand a media text in the language classroom: ambiguity as a strategy of manipulation // Edulearn 18 : Proceedings of $10^{\text {th }}$ International Conference on Education and New Learning Technologies (Palma de Mallorca, Spain, 2-4 July). Palma, IATED Academy. P. 1626-1633. DOI: 10.21125/ edulearn.2018.

Searle J., 1969. Speech Acts: An Essay in the Philosophy of Language. Cambridge : Cambridge University Press. 203 p.

White P. R. R., 2000. Media objectivity and the rhetoric of news story structure // Discourse and Community: Doing Functional Linguistics. Ventola E. (ed.). Tübingen : Verlag Gunter Narr. P. 379-394.

Wodak R., 2007. Critical discourse analysis // Qualitative research practice. L. : Sage. P. 185-201.

\section{СЛОВАРИ}

$C D$ - Cambridge Dictionary. URL: https://dictionary. cambridge.org/dictionary/english.

$M D$ - Macmillan Dictionary. URL: https://www. macmillandictionary.com/dictionary/british.

OELD - Oxford English Living Dictionaries. URL: https://en.oxforddictionaries.com/definition.

\section{REFERENCES}

Gayda S., 2014. Filosofiya stilya [Philosophy of Style]. Solganik G. Ya., Klushina N.I., Smirnova N.V., eds. Diskurs i stil: teoreticheskie i prikladnye aspekty: kollektiv. monogr. [Discourse and Style: Theoretical and Applied Aspects: Collective Monograph]. Moscow, Flinta Publ., Nauka Publ., pp. 9-17.

Dobrosklonskaya T.G., 2009. Lingvisticheskie sposoby vyrazheniya ideologicheskoy modalnosti v mediatekstakh [Linguistic Methods of Expression the Ideological Modality in Mediatexts]. Vestnik Moskovskogo universiteta. Seriya 19: Lingvistika i mezhkulturnaya kommunikatsiya 
[Bulletin of Moscow University. Series 19: Linguistics and Cross-Cultural Communication], no. 2, pp. 85-94.

Zemskaya E.A., 2004.Yazyk kak deyatelnost: Morfema. Slovo. Rech [Language as an Activity: Morpheme. Word. Speech]. Moscow, Yazyki slavyanskoy kultury Publ. 688 p.

Ivanova S.V., 2016. Lingvisticheskaya resursnaya baza informatsionnoy voyny: sozdanie effekta demonizatsii [Linguistic Resources Employed in an Information Warfare: Demonization Effect Techniques]. Politicheskaya lingvistika [Political Linguistics Journal], no. 5(59), pp. 28-37.

Ivanova S.V., Saduov R.T., 2008. Politicheskaya kommunikatsiya kak obrazets rechevogo manipulirovaniya [Political Communication as a Model of Verbal Manipulation]. Politicheskaya lingvistika [Political Linguistics Journal], no. 2(25), pp. 52-59.

Ivanova S.V., Chanysheva Z.Z., 2014. Tekhnologii diskursivnogo oformleniya slukhov v politicheskom diskurse massmedia [Rumor Introducing Discursive Technologies in Mass Media Political Discourse]. Politicheskaya lingvistika [Political Linguistics Journal], no. 2 (48), pp. 39-49.

Kara-Murza S. G., 2004. Manipulyatsiya soznaniem [Manipulation of Consciousness]. Moscow, Algoritm. Publ. 528 p.

Klushina N.I., 2008. Stilistika publitsisticheskogo teksta [The Style of Journalistic Text]. Moscow, MediaMir Publ. 244 p.

Klushina N. I., 2014. Eticheskie aspekty massovoy kommunikatsii [The Ethical Aspects of Mass Communication]. Vestnik Rossiyskogo universiteta druzhby narodov. Seriya: Lingvistika [Russian Journal of Linguistics], no. 1, pp. 59-66.

Komalova L., 2019. Reprezentatsiya verbalnogo obraza akta agressii $\mathrm{v}$ informatsionnom universume angloyazychnykh SMI [Representation of the Verbal Image of Aggression in the Informational Universe of the English-Language Mass Media]. Vestnik Rossiyskogo universiteta druzhby narodov. Seriya: Lingvistika [Russian Journal of Linguistics], vol. 23, no 1, pp. 149-164.

Kopnina G.A., 2014. Rechevoe manipulirovanie [Speech Manipulation]. Moscow, Flinta Publ., Nauka Publ. 170 p.

Larina T., Ozyumenko V., Ponomarenko E., 2011. Yazykovye mekhanizmy manipulirovaniya obshchestvennym mneniem $\mathrm{v}$ angliyskikh i russkikh informatsionnykh tekstakh [Language Mechanisms Used to Manipulate Public Opinion in English and Russian News Texts]. Vestnik Rossiyskogo universiteta druzhby narodov.
Seriya: Lingvistika [Russian Journal of Linguistics], no.1, pp. 28-37.

Ozyumenko V.I., 2017. Mediynyy diskurs v situatsii informatsionnoy voyny: Ot manipulyatsii - $\mathrm{k}$ agressii [Media Discourse in an Atmosphere of Information Warfare: From Manipulation to Aggression]. Vestnik Rossiyskogo universiteta druzhby narodov. Seriya: Lingvistika [Russian Journal of Linguistics], vol. 21, no. 1, pp. 203-220.

Postovalova V.I., 1982. Yazyk kak deyatelnost. Opyt interpretatsii kontseptsii $V$. Gumboldta [Language as an Activity. The Experience of Interpreting the Concept of V. Humboldt]. Moscow, Nauka Publ. 223 p.

Skovorodnikov A.P., Kopnina G.A., 2012. Teksty SMI kak pole rechevykh manipulyatsiy $i$ ikh razoblacheniy (na materiale rossiyskoy pressy) [Media Texts as a Field of Speech Manipulations and Their Disclosures (On the Material of the Russian Press)]. Lingvistika rechi. Mediastilistika: kollektiv. monogr., posvyashch. 80-letiyu prof. G.Ya. Solganika [Speech Linguistics. Mediastilistika. Collective Monograph Dedicated to the $80^{\text {th }}$ Anniversary of Professor G. Ya. Solganik]. Moscow, Flinta Publ., pp. 467-492.

Solopova O.A., Chudinov A.P., 2018. Diakhronicheskiy analiz metafor $\mathrm{v}$ britanskom korpuse tekstov: kolokola pobedy i Russia's V-Day [Diachronic Analysis of Political Metaphors in the British Corpus: From Victory Bells to Russia's V-Day]. Vestnik Rossiyskogo universiteta druzhby narodov. Seriya: Lingvistika [Russian Journal of Linguistics], vol. 22, no. 2, pp. 313-337.

Chernyavskaya V.E., 2006. Diskurs vlasti $i$ vlast diskursa. Problemy rechevogo vozdeystviya [Discourse of Power and Power of Discourse. Problems of Speech Exposure]. Moscow, Flinta Publ. 136 p.

Chudinov A.P., 2006. Politicheskaya lingvistika. [Political Linguistics]. Moscow, Nauka Publ., Flinta Publ. 256 p.

Sheygal E.I., 2004. Semiotika politicheskogo diskursa [Semiotics of Political Discourse]. Moscow, Gnosis Publ. 326 p.

Austin J.L., 1976. How to Do Things with Words. Oxford, New York, Oxford University Press. 192 p.

Bekalu M.A., 2006. Presupposition in News Discourse. Discourse and Society, vol. 17, no. 2, pp. 147-172.

Chilton P. 2011. Manipulation. Zienkowski J., Östman J.O., Verschueren, J., eds. Discursive Pragmatics. Amsterdam and Philadelphia, John Benjamins, pp. 176-189.

Clark C., 2010. Evidence ofEvidentiality in the QualityPress 1993 and 2005. Corpora, vol. 5, no. 2, pp. 139-160.

Weiss G., Wodak R., eds., 2007. Critical Discourse Analysis: Theory and Interdisciplinarity. 
London, Basingstoke, New York, Palgrave Macmillan. 336 p.

Dijk T.A., van, 2006. Discourse and Manipulation. Discourse and Society, vol. 17, iss. 3, pp. 359-383.

Dijk T.A., van, 2009. Society and Discourse. How Social Contexts Influence Text and Talk. Cambridge, Cambridge University Press. 287 p.

Empson W., 1966. Seven Types of Ambiguity. New York, New Directions. $256 \mathrm{p}$.

Fairclough N., 1989. Language and Power. Harlow and New York, Longman. 259 p.

Fairclough N., 1995. Critical Discourse Analysis: The Critical Study of Language. Harlow, Longman. $265 \mathrm{p}$.

Fairclough N., 2001. Critical Discourse Analysis as a Method in Social Scientific Research. Wodak R., Meyer M., eds. Methods of Critical Discourse Analysis. London, Thousand Oaks and New Delhi, Sage, pp. 121-139.

Fowler R., 1991. Language in the News. London, New York, Routledge. 254 p.

Gilbert D.T., Tafarodi R.W., Malone P.S., 1993.You Can't not Believe Everything You Read. Journal of Personality and Social Psychology, vol. 65, no. 2, pp. 221-233.

Levinson S., 1983. Pragmatics. Cambridge, Cambridge University Press. $420 \mathrm{p}$.

Lippmann W., 1922. Public Opinion. New York, Macmillan. $427 \mathrm{p}$.

McCombs M., Reynolds A., 2002. News Influence on Our Pictures of the World. Bryant J., Zillman D., eds. Media Effects: Advances in Theory and Research. Mahwah New Jersey, L. Elbaum Associates, pp. 1-18.

Wodak R., Meyer M., eds., 2001. Methods of Critical Discourse Analysis. London, Thousand Oaks, New Delhi, Sage. 200 p.
Ozyumenko V., Larina T., 2017. From Manipulation to Aggression: Analysis of Media Discourse in the Situation of Information Confrontation. $4^{\text {th }}$ International Multidisciplinary Scientific Conference on Social Sciences and Arts SGEM 2017. Vienna, HOFBURG Congress Centre, book 3, vol. 2, pp. 737-744.

Ozyumenko V., Larina T., 2018. How to Understand a Media Text in the Language Classroom: Ambiguity as a Strategy of Manipulation. Edulearn 18: Proceedings of $10^{\text {th }}$ International Conference on Education and New Learning Technologies (Palma de Mallorca, Spain, 2-4 July). Palma de Mallorca, IATED Academy, pp. 1626-1633. DOI: 10.21125/edulearn.2018.

Searle J., 1969. Speech Acts: An Essay in the Philosophy of Language. Cambridge, Cambridge University Press. 203 p.

White P.R.R., 2000. Media Objectivity and the Rhetoric of News Story Structure. Ventola E., ed. Discourse and Community: Doing Functional Linguistics. Tübingen, Verlag Gunter Narr, pp. 379-394.

Wodak R., 2007. Critical Discourse Analysis. Qualitative Research Practice. London, Sage, pp. 185-201.

\section{DICTIONARIES}

Cambridge Dictionary. URL: https://dictionary. cambridge.org/dictionary/english.

Macmillan Dictionary. URL: https://www. macmillandictionary.com/dictionary/british.

Oxford English Living Dictionaries. URL: https:// en.oxforddictionaries.com/definition.

\section{Information about the Author}

Vladimir I. Ozyumenko, Candidate of Sciences (Philology), Associate Professor, Department of Foreign Languages, Peoples' Friendship University of Russia, Miklukho-Maklaya St., 6, 117198 Moscow, Russia, ozyumenko-vi@rudn.university, https://orcid.org/0000-0001-7587-3007

\section{Информация об авторе}

Владимир Иванович Озюменко, кандидат филологических наук, доцент кафедры иностранных языков, Российский университет дружбы народов, ул. Миклухо-Маклая, 6, 117198 г. Москва, Россия, ozyumenko-vi@rudn.university, https://orcid.org/0000-0001-7587-3007 